\title{
Usos e apropriações dos celulares: uma perspectiva educacional
}

\author{
Alan César Belo Angeluci* \\ Silvana Comunian Soares** \\ Adriana Barroso de Azevedo ${ }^{* * *}$
}

\section{Resumo}

Abrangendo uma nova cultura digital instaurada no campo educacional.

O texto busca compreender as particularidades dos usos e apropriações das principais mídias móveis utilizadas por jovens alunos brasileiros. A metodologia abrangeu pesquisa de campo, com aplicação de questionário, envolvendo a escolha de uma Escola Municipal, localizada no município de São Caetano do Sul, São Paulo, como local para coleta de dados quantitativos. O questionário formulado teve o objetivo de cobrir os objetivos específicos da pesquisa e dispôs de oito perguntas. Ademais, os resultados apontam que a cultura comunicacional da escola está distante das práticas cotidianas de comunicação digital dos alunos e, ainda, na perspectiva do aluno, o celular é capaz de incentivá-los a estudar mais, aumentando ainda a autonomia e troca de conhecimentos no ambiente escolar.

Palavras-chave: tecnologia; jovens; ensino-aprendizagem; celulares; mídias móveis.

* Professor permanente no Programa de Pós-Graduação em Comunicação e na Graduação em Comunicação Social na Universidade Municipal de São Caetano do Sul (USCS). Pós-doutor no Department of Radio-Television-Film, University of Texas at Austin (EUA). Doutor em Ciências com ênfase em Sistemas Eletrônicos EPUSP, com doutorado Sanduíche na University of Brighton, Inglaterra. aangeluci@uscs.edu.br.

** Mestranda em Educação pela Universidade Municipal de São Caetano do Sul (USCS). Pós-graduada em Engenharia de Software pela Faculdade de Informática e Administração Paulista (FIAP), extensão no Babson College, Wellesley, MA (EUA).silvana.soares@uscs.edu.br.

*** Pós-doutora em Educação e Doutora em Comunicação Social, Mestre em Educação e Pedagoga. Docente Permanente do Programa de Pós-Graduação em Educação e Pró-Reitora de Pós-Graduação e Pesquisa da Universidade Metodista de São Paulo. adriana.azevedo@metodista.br. 


\section{Cellular uses and appropriations: an educational perspective}

\section{Abstract}

Making a new digital culture established in the educational field, the text seeks to understand the characteristics of the uses and appropriations of the main mobile media by young Brazilian students. The methodology covered a field survey, with the application of a questionnaire, involving the choice of a Municipal School, located in the Municipality of São Caetano do Sul, São Paulo, as a place to collect quantitative data. The formulated questionnaire had the objective of covering the specific objectives of the research and had 8 questions. In addition, the results point out that the communicational culture of the school is far from the daily practices of digital communication of the students and also, from the student's perspective, the cell phone is capable of encouraging them to study more, increasing autonomy and exchange of knowledge in the school environment.

Keywords: technology; young; teaching-learning; cell phones; mobile media.

\section{Usos y apropiaciones de los móviles: una pers- pectiva educativa}

\section{Resumen}

En el marco de una nueva cultura digital instaurada en el campo educativo, el texto busca comprender las particularidades de los usos y apropiaciones de los principales medios móviles por jóvenes alumnos brasileños. La metodología abarcó investigación de campo, con aplicación de cuestionario, involucrando la elección de una Escuela Municipal, ubicada en el Municipio de São Caetano do Sul, São Paulo, como local para la recolección de datos cuantitativos. El cuestionario formulado tuvo el objetivo de cubrir los objetivos específicos de la investigación y dispuso de ocho preguntas. Además, los resultados apuntan que la cultura comunicacional de la escuela está distante de las prácticas cotidianas de comunicación digital de los alumnos y aún, en la perspectiva del alumno, el móvil es capaz de incentivarlos a estudiar más, aumentando aún la autonomía y el intercambio de conocimientos en el ambiente escolar.

Palabras clave: tecnología; young; enseñanza y el aprendizaje; móvil; medios móviles. 


\section{Introdução}

A sociedade contemporânea convive com o crescente uso de tecnologias de informação e comunicação (TIC), mais notadamente o de aparelhos celulares e de outras tecnologias smart. Para além das funções básicas ou primárias, estes dispositivos têm provocado alterações em usos e comportamentos de indivíduos e comunidades nas suas formas de se comunicar e interagir.

O impacto dessas tecnologias, no entanto, tem gerado especial atenção às dinâmicas dos ambientes escolares, mais especificamente dentro da sala de aula. Por mais que a Unesco ${ }^{1}$ tenha definido, em 2013, políticas para a aprendizagem móvel, incentivando e destacando a importância da inserção de tecnologias móveis dentro da sala de aula, a realidade em grande parte das instituições de ensino é outra: gestores e professores, em sua grande maioria, enxergam nos dispositivos móveis uma ameaça ao processo de ensino-aprendizagem, quando na verdade deveriam se debruçar sobre novas práticas e políticas de uso dos aparelhos com foco no desenvolvimento de literacias digitais. Há uma nítida cultura de rejeição à inclusão de tecnologias - quando ocorre, é feita de maneira a mimetizar práticas das plataformas tradicionais.

$\mathrm{Na}$ outra ponta estão os alunos, imersos em uma cultura digital distante das práticas escolares, que transitam bem entre as plataformas digitais, mas acabam se dedicando a processos comunicacionais móveis desligados dos processos de ensino-aprendizagem, e que, muitas vezes, pouco contribuem para a sua formação crítica e humanística. Para a escola, rendida à cultura do controle, resta a postura da proibição e da negação do novo e do diálogo sobre meios e formas de apropriações adequadas dessa tecnologia dentro do ambiente escolar.

O interesse deste estudo centra-se na relação do aluno com seu entorno escolar, em que normas e práticas tradicionais e as tecnologias móveis estão em constante tensão. Partindo de um referencial teórico composto por autores como Francisco Rüdiger, Sherry Turkle, Luciano Floridi, Roxane Rojo, James Katz, Rui Fava, um conjunto de dados quanti-

\footnotetext{
1 Disponível em: < http://unesdoc.unesco.org/images/0022/002277/ 227770por.pdf >. Acesso em: 21 ago. 2017.
} 
tativos extraídos de um questionário aplicado junto a estudantes de ensino médio e técnico foi coletado com o objetivo de analisar aspectos sociais, expectativas, riscos e possíveis contramedidas em relação ao uso de aparelhos celulares no contexto escolar.

O texto estrutura-se, inicialmente, a partir de uma reflexão sobre a evolução e consumo de mídias digitais e do comportamento de jovens consumidores de tecnologia e conteúdo digital. Nos tópicos posteriores, são apresentados os procedimentos metodológicos utilizados no estudo e análise a partir dos dados obtidos em campo.

\section{Referencial teórico}

Em recente pesquisa realizada pela Fundação Telefônica Vivo (2016), com 1.440 jovens brasileiros, de 15 a 29 anos, das cinco regiões do Brasil, constatou-se que $85 \%$ desses jovens (figura 1) acessam à internet por meio de aparelhos celulares, independentemente de sua classe social. Este número teve um aumento exponencial de 102\% em relação à mesma pesquisa no ano de 2013. As atividades mais executadas pelos jovens (figura 2), ao fazer uso do aparelho celular, correspondem a: conversar por mensagens instantâneas; acessar redes sociais e trocar e-mails. Até 2015, no Brasil, 93\% de brasileiros tinha posse de equipamentos celulares, segundo pesquisa TIC Domicílios e Usuários 2015. Equipamentos como computador de mesa, computador portátil (notebook) e tablet, juntos, não atingiam 80\%.

Figura 1 - Frequência de uso de aparelhos para acesso à Internet.

\begin{tabular}{lcc}
\hline Dispositivo & 2013 & 2015 \\
\hline Celular & $42 \%$ & $85 \%$ \\
\hline Computador de Mesa & $33 \%$ & $7 \%$ \\
\hline Computador Portátil & $22 \%$ & $6 \%$ \\
\hline Tablet & $3 \%$ & $1 \%$ \\
\hline
\end{tabular}

Fonte: adaptado de Fundação Telefônica Vivo, 2016, p. 23. 
Figura 2-Atividades mais/menos praticadas ao navegar na Internet.
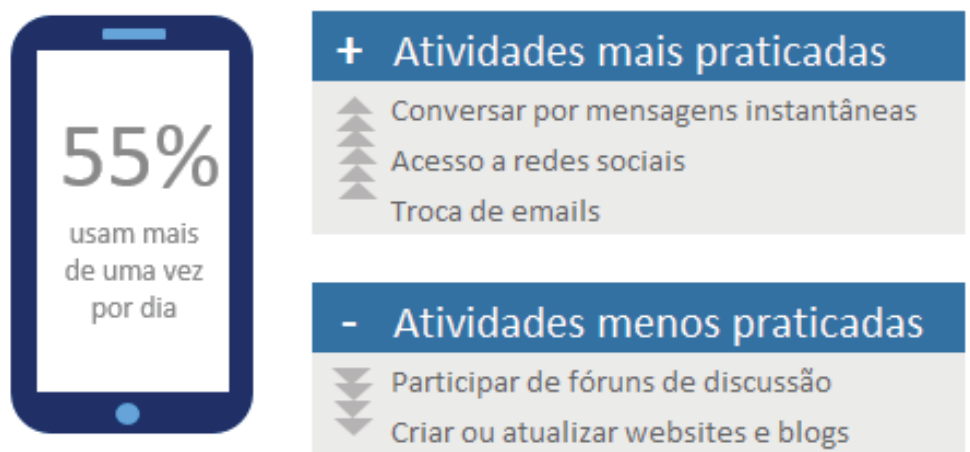

Fonte: adaptado de Fundação Telefônica Vivo, 2016, p. 25.

Em consonância a esses dados, de acordo com pesquisa realizada pela comScore (2017), o uso de smartphones duplicou nos últimos três anos e, desde 2014, tem impulsionado o crescimento do tempo de mídia digital, o que eleva o tempo gasto, por pessoa, em celular: a média diária, até dezembro/2016, encontrava-se em torno de 2 horas e 51 minutos. Este número continua progredindo, e de acordo com a fonte pode chegar a um trilhão de minutos de consumo por mês, representando quase o dobro do uso de internet, no desktop, no seu auge.

Dentro deste cenário de crescimento exponencial de consumo de mídias e dispositivos móveis, podemos estabelecer ou correlacionar a formação de uma nova cultura, a "cibercultura”, descrita por Rüdiger (2013, p. 11) como sendo

[...] a expressão que serve à consciência mais ilustrada para designar o conjunto dos fenômenos cotidianos agenciado ou promovido com o progresso das telemáticas e seus maquinismos. Afinando o conceito um pouco mais, poderia bem ser definida como a formação histórica, ao mesmo tempo prática e simbólica, de cunho cotidiano, que se expande com base no desenvolvimento das novas tecnologias eletrônicas de comunicação. 
Floridi (2013), paralelamente, enfatiza que as novas tecnologias emergentes nos conduzem para uma alteração da percepção sobre nós mesmos e sobre a realidade, do relacionamento com os outros e com nossa própria realidade. Somos levados à hibridização entre virtual e real, entre humano e máquina. Os tempos sugerem abundância e não linearidade da informação, ao invés de escassez e centralização. O termo on-life, cunhado por Floridi, explicita a transcendência entre vida on-line e off-line, onde não há mais distinção entre estar conectado e desconectado.

Nessa nova realidade, de conexão plena e global, os jovens mantêm grande familiaridade com os aparatos tecnológicos e as novas formas de relacionamento. "[...] diferentemente da geração mais velha, não há mais medo de perder contato com algo ou alguém, pois as relações são baseadas na ideia de contato perpétuo" (KATZ; AAKHUS, 2002). As relações estabelecidas são frágeis e suscetíveis à tempestividade do contato. Aliado a isso, Turkle defende que nossa capacidade de interagir uns com os outros nos remove de uma situação particular. Passamos a viver no tempo e lugar limitado. Estamos perdendo a conexão com outros seres humanos e substituindo-a por contatos virtuais que não são tão flexíveis, viáveis ou reais (TURKLE, 2012). Rüdiger (2013, p. 12) corrobora com esta avaliação, enfatizando que

As transformações provocadas pela tecnociência moderna acabaram, com o tempo, extrapolando o registro das atividades produtivas e, assim, começaram a influir na existência cotidiana. Agora, passa nosso mundo por um processo cada vez menos silencioso de metamorfose, conduzida tecnologicamente, cujos efeitos, embora se projetando de maneira longínqua, quando não são objeto dos noticiários, já se antecipam em todo tipo de obras de ficção e em muitos fenômenos de costumes, despertando diversas formas de preocupação em todos aqueles que nutrem alguma curiosidade pela fortuna de nossa civilização.

Apesar de as pesquisas apontarem grande preferência, por parte dos jovens, pelo uso de tecnologia no ambiente escolar, os processos didáticos contemporâneos ainda esbarram em fatores de resistência quanto à mudança dos padrões de ensino, por parte de parcela significativa de educadores e professores. 
Estes profissionais mantêm, ainda, uma visão tradicionalista, visualizando a tecnologia e, particularmente, o uso de aparelhos celulares em sala de aula, como direcionada ao lazer, não sendo possível materializar o uso da tecnologia com o processo de aprender. A análise de Fava (2016, p. 298) sobre uma nova proposta pedagógica corrobora com esse estudo ao elencar que

O velho modelo de sala de aula notoriamente não atende às novas necessidades. Trata-se de um modelo essencialmente passivo, ao passo que o mundo requer um processamento, acionamento de informações mais célere, mais ativo. $\mathrm{O}$ modelo de enfileirar estudantes com currículos lineares, torcendo para que granjeiem algo ao longo do verboso caminho. Não é inquestionável se esse foi o melhor modelo 100 anos atrás; se era, indubitavelmente não é mais.

Ao classificarmos as atuais abordagens didático-pedagógicas como sendo tradicionalistas, paralelamente, Fava (2016, p. 314) discursa a respeito, trazendo maior completude a este olhar:

O tradicionalismo ainda é muito presente no sistema educacional brasileiro, as metamorfoses existem, mas é tudo muito intrincado, laborioso. Aparentemente todos estão abertos ao diferente, entretanto, a cultura do ensino tradicional, a legislação, o regulatório dificultam qualquer inovação disruptiva, fazendo com que a mutação ande a passos remansosos.

Em contrapartida, a proibição do uso de celulares em sala de aula pode ser considerada um reflexo da sustentação dos citados métodos tradicionais e/ou clássicos de ensino-aprendizagem dentro do contexto escolar, que considera que tal uso compromete o desenvolvimento e concentração dos alunos. Segundo o Projeto de Lei n. ${ }^{\circ}$ 2.246-A, artigo $1^{\circ}$, "[...] fica proibido o uso de telefone celular nas escolas públicas do país" (BRASIL, 2007), sob a justificativa de

[...] assegurar a essência do ambiente escolar, onde a atenção do aluno deve estar integralmente direcionada aos estudos, na fixação do aprendizado passado pelos professores, sem que nada possa competir ou desviá-lo desse objetivo. $\mathrm{O}$ uso do celular no ambiente escolar compromete o de- 
senvolvimento e concentração dos alunos, e são preocupantes os relatos de professores e alunos de como é comum o uso do celular dentro das salas de aulas. (BRASIL, 2007).

Rojo (2008, p. ?), há quase uma década, já afirmava que “[...] o surgimento e a ampliação contínua de acesso às tecnologias digitais da comunicação e informação (computadores pessoais, mas também celulares, tocadores de MP3, TVs digitais, entre outras)" implicam na necessidade de mudanças em relação aos letramentos ${ }^{2}$ socialmente requeridos. E, adicionalmente, complementa que "o letramento escolar"3 tal como o conhecemos, voltado principalmente para as práticas de leitura e escrita de textos em gêneros escolares (anotações, resumos, resenhas, ensaios, dissertações, descrições, narrações e relatos, exercícios, instruções, questionários, dentre outros)" não será suficiente para atender as exigências do mundo contemporâneo, sendo necessário ampliar e democratizar novas formas de letramento, tal como o digital (ROJO, 2008).

\section{Metodologia}

A partir desta reflexão, foi realizada uma pesquisa de campo envolvendo a escolha de uma escola municipal, localizada no município de São Caetano do Sul, São Paulo, Brasil, como local para coleta de dados quantitativos. O perfil de respondentes definido contemplava estudantes de ensino médio e ensino técnico, na faixa etária de adolescentes, compreendendo 174 participantes $(\mathrm{N}=174)$. O questionário formulado teve o objetivo de cobrir os objetivos específicos da pesquisa e dispõe de 8 (oito) perguntas, que analisam o grau de concordância, frequência, preferência, ocorrência e opinião sobre questões relacionadas ao uso de celular dentro

2 Letramentos: “[...] são práticas sociais e culturais que tem sentidos e finalidades específicos dentro de um grupo social, ajuda a manter a coesão e a identidade do grupo, são apreendidos em eventos coletivos de uso da leitura e da escrita e, por isso, são diferentes em diferentes contextos socioculturais" (BUZATO, 2006).

3 Letramento escolar: são práticas sociais mediadas pela escrita, valorizadas pela escola. 
da sala de aula, além de questões sobre o perfil do respondente. O questionário foi distribuído de forma on-line, utilizando-se o Google Forms ${ }^{4}$.

\section{Análise qualitativa}

A pesquisa em campo refere-se a uma amostra de $\mathrm{N}=174$, sendo $66 \%$ do gênero feminino e 34\% do gênero masculino, dos quais $97 \%$ são alunos do ensino médio e 3\% são alunos do ensino técnico/profissionalizante de escola municipal localizada no município de São Caetano do Sul, São Paulo, Brasil.

\section{O perfil do jovem conectado}

O percentual de 94,8\% dos jovens são proprietários de aparelhos celulares (smartphones), o que implica dizer que um pouco mais da metade dos participantes da pesquisa $(52,1 \%)$ preferem celular ao uso de computador pessoal (desktop), cujo percentual representou 49,4\%. No entanto, observa-se que a grande maioria dos proprietários de celular ainda dispõe de notebooks (72,4\%), o que revela uma adesão dessa geração ao ambiente de comunicação móvel. Isso se explica, em parte, pela emergência de novas tecnologias móveis disponíveis no mercado, mas também por um processo cultural de migração de ambientes desktop para móveis, já discutidos anteriormente por Angeluci (2016).

Ao observar sob a ótica de preferência de uso, o notebook estabelece-se em $1^{\circ}$ lugar com 32\% (Muita Preferência), seguido de tablet (26\%), computador de mesa e livros $(24 \%)$ e por último temos o smartphone com $13 \%$. Estes dados configuram-se contrários quanto à posse de equipamentos. Apesar de 94,8\% dos jovens disporem de smartphone, apenas 13\% afirmam que tem "Muita Preferência” em relação ao seu uso. No entanto, quando se observa o indicador de "Alguma Preferência", smartphone domina com $76 \%$ e apenas $1 \%$ do público afirma ter "Nenhuma Preferência" a este dispositivo. Os dados demonstram claramente a tendência ao uso de smartphones em relação a outros tipos de dispositivos quando se compara os indicadores de neutralidade e pouca/nenhuma preferência.

4 Google Forms: trata-se de uma ferramenta da Google para criação de formulários personalizados para pesquisas e questionários, garantindo o anonimato dos participantes. 
Os livros apresentaram retornos de grande destaque, comparáveis ao computador de mesa e tablet, representando ainda uma fonte de consulta relevante, confirmando que que os livros físicos ainda são fontes de consumo de ampla parcela dos respondentes.

Quanto ao uso que os jovens fazem das ferramentas, observa-se a navegação em redes sociais, aplicativos de streaming de vídeo, troca de mensagens e imagens, sendo: Facebook (94,8\%), WhatsApp (95,4\%), Instagram (77,6\%), Netflix (73\%), Snapchat (70,1\%) e Twitter (53,4\%). As ocorrências mais baixas referem-se a Moodle (ambiente interativo escolar) e Aplicativo de Paquera, onde ambas perfazem a soma de 6,3\%. É relevante ressaltar a aproximação entre Facebook e WhatsApp, com percentuais quase similares, explicitando a grande preferência de uso, seja pela facilidade de manuseio e/ou proliferação dessas ferramentas à grande massa, em razão do seu alto potencial de interatividade e recursos que permitem conversações síncronas e assíncronas.

\section{O perfil do jovem [aluno] conectado}

Ao analisar o perfil do aluno que utiliza aparelho celular em sala de aula, observa-se as seguintes características principais: o uso do aparelho celular destina-se, em sua grande maioria, a acessar conteúdos de relacionamento (conversar com amigos, familiares, namorado, namorada, desconhecidos). No entanto, ao observar isoladamente o tema "educação", o indicador de "uma vez por dia" é maior em relação a todos os demais temas (gráfico 1). Independentemente, os resultados demonstram que o tema educação, dentro da sala de aula, quando acessado, concorre fortemente com temas aleatórios, sem fins pedagógicos (diversão, relacionamento e notícias). O aluno declara que, de fato, o uso do celular, dentro de sala de aula, não é exclusivo para pesquisas e estudos (50\% afirma a não exclusividade).

Em paralelo a isso, este estudo demonstrou ainda que $89 \%$ dos jovens discordam que o uso de aparelho celular em sala de aula apenas "atrapalha" o ensino e, inclusive, 85\% afirmam que não usam o celular, também em sala de aula, apenas para “diversão".

Apesar do uso constante e aleatório, os jovens entendem (84\% gráfico 2) que o uso do celular poderia ser liberado em sala de aula, mas 




EDUCAÇÃO \& LINGUAGEM • V. 21 • N. 1 •23-40 • JAN.-JUN. 2018 
aceitam que sejam impostas restrições nesse uso. Isso demonstra certo grau de compreensão acerca dos impactos que podem decorrer de um uso indiscriminado e o entendimento do local onde estão inseridos. Ainda 64\% do público discorda ou discorda fortemente que o celular deveria ser liberado para uso em qualquer momento, ou seja, sem restrição alguma imposta.

Gráfico 2 - Uso do celular em aula deve ser liberado com restrições

\section{O uso do celular em aula deve ser liberado, mas com certas restrições.}

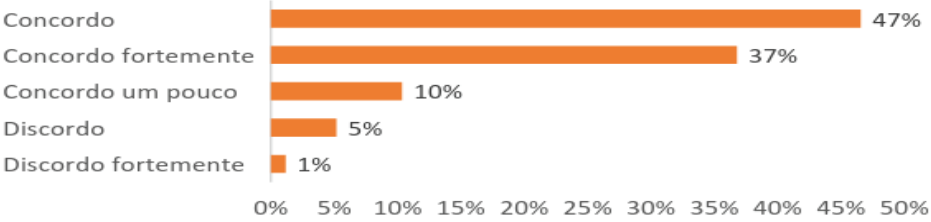

Fonte: autores.

\section{O processo de ensino-aprendizagem}

Ao adentrarmos a sala de aula e observarmos como o celular é vivenciado nesse cenário, constata-se que $63 \%$ dos jovens (gráfico 3 concordam e concordam fortemente) acreditam que o celular seja capaz de incentivar o aluno a estudar mais, ratificado por $89 \%$ que discordam ou discordam fortemente que o celular seja capaz de atrapalhar o processo de ensino-aprendizagem e $83 \%$ que discordam ou discordam fortemente que o celular "atrapalha" os jovens.

Gráfico 3 - Uso do celular para uma atividade de aula incentiva o aluno a estudar mais

\section{Usar o celular para uma atividade de aula incentiva o aluno a estudar mais.}



Fonte: autores. 
Aliado aos dados, Floridi nos chama a atenção para a abundância de informação trazer consequências às capacidades cognitivas do ser humano, onde sobrecarregados de dados, tendemos a nos tornar mais distraídos e menos atentos ao momento presente (FLORIDI, 2014). Frente a isso, nosso estudo demonstra que 51\% (concordam um pouco, concordam ou concordam fortemente) dos jovens acreditam que o celular, muitas vezes, é responsável por desviar sua concentração durante uma explicação (gráfico 4). Este é um fator relevante e que deve ser considerado quando da inserção do celular em ambiente escolar; no entanto, outros fatores também devem ser considerados em relação aos benefícios advindos dessa prática.

Gráfico 4-O celular muitas vezes tira a concentração durante uma explicação

Fonte: autores.

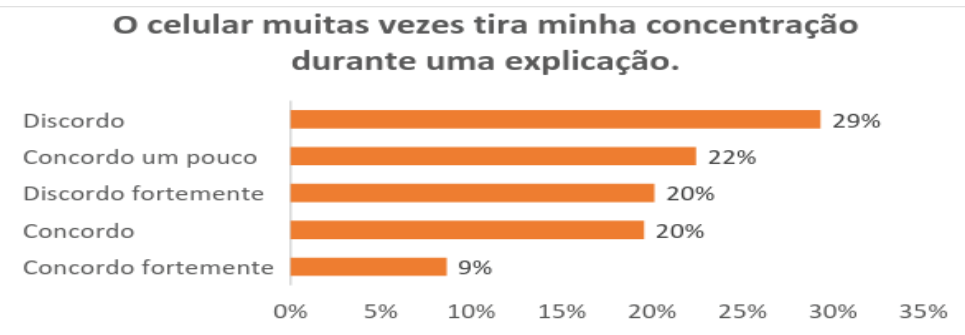

Ferramentas disponíveis, por intermédio da internet, também são citadas como estimuladoras do processo de ensino-aprendizagem. Nesse contexto, 92\% concordam totalmente (figura 3) que a internet possibilita maior acesso a conhecimentos e informações. Corroborando com esta perspectiva, este estudo retornou que $87 \%$ dos jovens afirmam (gráfico 5) que o celular pode se configurar como auxílio em sala, aprimorando o conhecimento de outras formas. 
Figura 3 - Percepções e atitudes dos jovens sobre a Internet

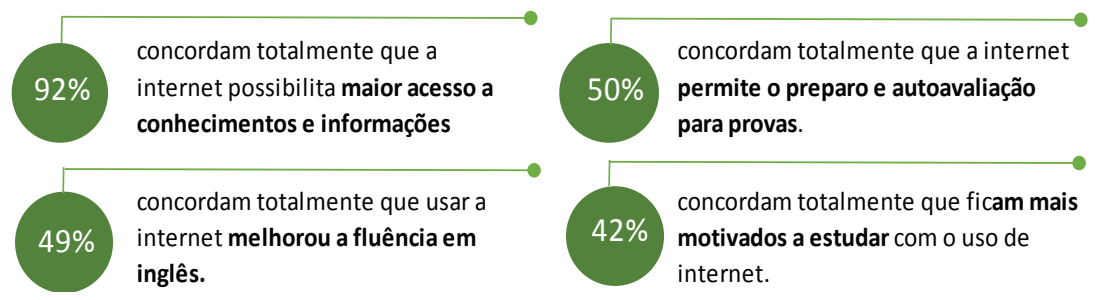

Fonte: adaptado de Fundação Telefônica Vivo, 2016, p. 111.

Gráfico 5-O celular pode ser um auxílio em sala e aprimora o conhecimento de outras formas

\section{O celular pode ser um auxílio em sala e aprimora o conhecimento de outras formas.}

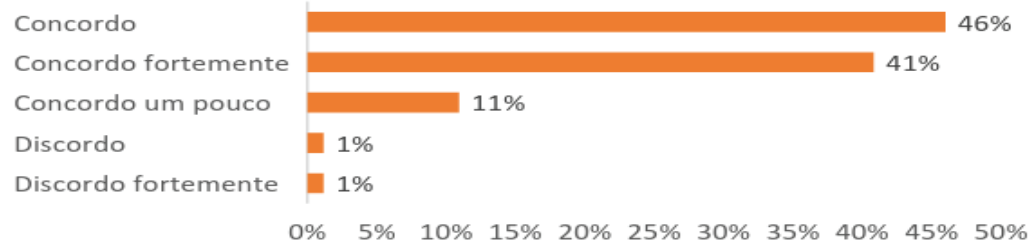

Fonte: autores.

Os jovens demonstram, ainda, clareza acerca dos impactos do uso de celulares em ambiente escolar, onde 68\% (gráfico 6) observam que sua escola dispõe de regras que se encontram aquém da realidade do dia a dia. Ademais, $41 \%$ afirmam que seus professores não estão aptos a lidar com tal realidade, utilizando novas tecnologias para fins didáticos (gráfico 7). 
Gráfico 6-As regras de uso de celular dentro da escola estão distantes da realidade do dia-a-dia

\section{As regras de uso de celular dentro da escola estão distantes da nossa realidade do dia a dia.}

Concordo um pouco
Discordo
Concordo
Concordo fortemente
Discordo fortemente

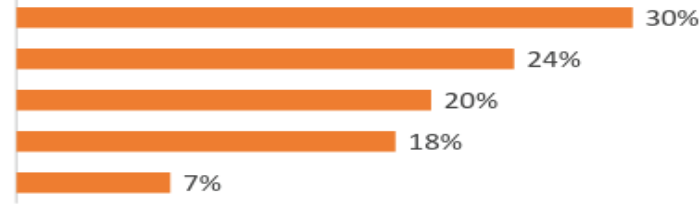

$\begin{array}{llllllll}0 & 5 \% & 10 \% & 15 \% & 20 \% & 25 \% & 30 \% & 35 \%\end{array}$

Fonte: autores.

Gráfico 7 - A maioria dos professores sabe utilizar bem novas tecnologias, como os celulares, para fins didáticos


Fonte: autores.

\section{Considerações finais}

Os celulares fazem parte do cotidiano de jovens brasileiros e cada vez mais encontram-se inseridos em novas nuances comportamentais advindas da transformação digital vivenciada nos dias atuais. $\mathrm{Na}$ busca pelo entendimento deste novo comportamento, este estudo dedica-se à investigação referente aos usos e apropriações das mídias móveis predominantes entre jovens brasileiros. Especificamente, esse levantamento refere-se a um recorte exíguo de uma comunidade e contexto muito específico: 174 (cento e setenta e quatro) jovens estudantes, do ensino médio e do ensino técnico/ profissionalizante, de Escola Municipal do Estado de São Paulo, Brasil. 
A metodologia abrangeu pesquisa de campo, com aplicação de questionário para coleta de dados quantitativos. O questionário primou pela cobertura dos objetivos específicos da pesquisa e dispôs de oito perguntas, que analisavam o grau de preferência, concordância, frequência, ocorrência e opinião sobre quesitos relacionados ao uso de celular dentro do contexto escolar.

Apesar de os dados coletados serem estatisticamente relevantes e apropriados para a abordagem, não podemos assumir que essa amostra é prova substancial dos impactos e processos envolvidos no uso de aparelho celular em sala de aula, relacionado ao processo de ensino-aprendizagem, nem tampouco é capaz de estabelecer assertivamente os padrões comportamentais envolvidos; no entanto, revela-se como uma importante fotografia que se prova estar em consonância com outras pesquisas de grande envergadura, credenciando os dados aqui apresentados e discutidos.

Os resultados destacam um distanciamento entre a cultura comunicacional da instituição escolar e as atuais práticas cotidianas de comunicação digital vivenciadas hodiernamente pelos alunos, cuja manutenção tem sido realizada através de métodos tradicionais de ensino-aprendizagem. Os jovens apontam que o uso adequado e controlado dos recursos fornecidos pelo aparelho celular, dentro do contexto escolar, seja capaz de incentivar o aluno a estudar mais, propiciando o aumento da autonomia e troca de conhecimentos no ambiente escolar. Os jovens, dentro desse contexto, detêm ainda conhecimento referente aos impactos oriundos do uso inadequado de celulares.

Este estudo clarifica o tema nos direcionando ao conceito de personalização do ensino, onde as instituições, e particularmente os educadores, devem direcionar seus esforços para a individualidade dos aprendizes, o que não implica substituir o professor pelo uso da tecnologia. $\mathrm{O}$ professor deve abarcar nessa nova era do conhecimento, apropriar-se de ferramentas para ampliação e construção do aprendizado, e repensar seu papel de transmissor para mediador, desenvolvendo no aluno a disposição de aprender a aprender, fomentando a autonomia e estimulando-o a buscar por informações. 


\section{Agradecimentos}

Agradecemos ao apoio financeiro do Conselho Nacional de Desenvolvimento Científico e Tecnológico (CNPq), Edital CNPq Universal 01/2016, processo n. ${ }^{\circ} 424802 / 2016-3$.

\section{Referências}

ANGELUCI, A. C. B. Do Desktop para o Mobile: usos e apropriações de conteúdos digitais por jovens de diferentes extratos sociais. 2016. 69 f. Relatório (PósDoutorado) - Escolar de Comunicações e Artes, Universidade de São Paulo, São Paulo, 2016.

BRASIL, Projeto de Lei 2.246-A, de 2007. Brasília, DF: Câmara dos Deputados, 2007. Disponível em: <http://www.camara.gov.br/proposicoesWeb/prop_mostrarintegra?codteor $=517286>$. Acesso em: 3 fev. 2018.

BUZATO, M. E. K. Letramento digital: um lugar para pensar em internet, educação e oportunidades. In: CONGRESSO IBERO-AMERICANO EDUCAREDE, 3., São Paulo, 2006. Anais... São Paulo: CENPEC, 2006. [n.p.].

COMSCORE. 2017 U.S. Cross-Plataform Future in Focus. Disponível em: <https://www.comscore.com/Insights/Presentations-and-Whitepapers/2017/ 2017-US-Cross-Platform-Future-in-Focus>. Acesso em: 3 fev. 2018.

FAVA, Rui. Educação para o século XXI: a era do indivíduo digital. São Paulo: Saraiva, 2016.

FLORIDI, L. The OnLife Manifesto: Being Human in a Hyper Connected Era. Springer International Publishing, 2014. 264 páginas.

FUNDAÇÃO TELEFÔNICA VIVO. Juventude conectada. São Paulo: Fundação Telefônica, 2014.

FUNDAÇÃO TELEFÔNICA VIVO. Juventude conectada 2. São Paulo: Fundação Telefônica Vivo, 2016.

GIL, A. C. Como elaborar projetos de pesquisa. 4. ed. São Paulo: Atlas, 2002.

KATZ, J. E.; AAKHUS, M. Perpetual contact: Mobile communication, private talk, public performance. Cambridge: Cambridge University Press, 2002. 
LIVINGSTONE, S. Taking Risk Opportunities in Youthful content creation: teenagers use of social networking sites for intimacy privacy and self-expression. New media \& society, v. 10, n. 3, p. 393-411, 2008.

NÚCLEO DE INFORMAÇÃO E COORDENAÇÃO DO PONTO BR. Pesquisa sobre o uso das tecnologias de informação e comunicação nos domicílios brasileiros: TIC domicílios 2015. São Paulo: Comitê Gestor da Internet no Brasil, 2016.

ROJO, R. H. O letramento escolar e os textos da divulgação científica: a apropriação dos gêneros do discurso na escola. Revista Linguagem em (Dis)curso, v. 8, n. 3, p. 581-612, set./dez. 2008.

RÜDIGER, F. As teorias da cibercultura: perspectivas, questões e autores. 2. ed. Porto Alegre: Sulina, 2013.

SEVERINO, A. J. Metodologia do Trabalho Científico. 24. ed. São Paulo: Saraiva, 2007.

SOARES, M. Letramento: um tema em três gêneros. Belo Horizonte: Autêntica, 1998.

TURKLE, Sherry. Alone Together: Why We Expect More from Technology and Less from Each Other. New York: Basic Books, 2012.

Submetido em: 8-3-2018

Aceito em: 21-3-2018 